Tohoku J. Exp. Med., 2005, 205, 157-169

\title{
The Evaluation of First Aid and Basic Life Support Training for The First Year University Students
}

\author{
Kerim Hakan Altintaş, Dilek Aslan, Ali Naci Yildiz, Nüket Subaşi, Melì \\ Elçin, ${ }^{1}$ Orhan Odabaşı, ${ }^{1}$ Nazmi Bilír and İsKender SAyeK ${ }^{1}$ \\ Department of Public Health and ${ }^{1}$ Department of Medical Education and \\ Informatics, Faculty of Medicine, Hacettepe University, Ankara, Turkey
}

\begin{abstract}
Altintaş, K.H., Aslan, D., Yildiz, A.N., Subaşı, N., Elçin, M., Odabaşı, O., Bilirir, N. and SAYEK, I. The Evaluation of First Aid and Basic Life Support Training for The First Year University Students. Tohoku J. Exp. Med., 2005, 205 (2), 157-169 — In Turkey, the first aiders are few in quantity and yet they are required in many settings, such as earthquakes. It was thought that training first year university students in first aid and basic life support (FA-BLS) techniques would serve to increase the number of first aiders. It was also thought that another problem, the lack of first aid trainers, might be addressed by training medical students to perform this function. A project aimed at training first year university students in FA-BLS was conducted at Hacettepe University. In the first phase, medical student first aid trainers (MeSFAT) were trained in FA-BLS training techniques by academic trainers and in the second phase, first year university students were trained in FA-BLS techniques by these peer trainers under the academic trainers' supervision. The purpose of this study was to assess the participants' evaluation of this project and to propose a new program to increase the number of first aiders in the country. In total, 31 medical students were certified as MeSFATs and 12 of these trained 40 first year university students in FA-BLS. Various questionnaires were applied to the participants to determine their evaluation of the training program. Most of the participants and the authors considered the program to be successful and effective. This method may be used to increase the number of first aid trainers and first aiders in the community. —— first aid; basic life support; training; student; peer

(C) 2005 Tohoku University Medical Press
\end{abstract}

First aid and basic life support (FA-BLS) are components of chain of survival for a person experiencing a life-threatening emergency. In Turkey, the first aiders are few in quantity and yet they are required in many settings. Almost 98\% of Turkey's land is in an earthquake zone (Sarp 1999); earthquakes occur frequently. The Marmara earthquake of August 17, 1999 claimed about 17,480 lives and injured 49,953 people
(Prime Ministry, Turkey 2000). External relief is often unavailable for up to 24 to 48 hours after an earthquake occurs (Waeckerle 1991). Safar studied the 1980 earthquake in Italy and concluded that $25 \%$ to $50 \%$ of victims who were injured and died slowly could have been saved if life-saving FA had been rendered immediately (Safar 1986; Liang et al. 2001). 5,000 to 6,000 people die and about 100,000 people are injured every year due

Received October 4, 2004; revision accepted for publication December 13, 2004.

Address for reprints: Kerim Hakan Altıntaş, M.D., Assist. Prof. of Public Health, Department of Public Health,

Faculty of Medicine, Hacettepe University, 06100, Ankara, Turkey.

e-mail: hakana@hacettepe.edu.tr,kha_1964@yahoo.com 
to road accidents (Altıntaş 1998). 1,000 workers die and 2,000 to 3,000 workers become incapacitated in occupational accidents (Altıntaş 1998). Deaths due to injuries could be decreased by 15-18\% with appropriate FA-BLS (Ministry of Health, Turkey 1992). $10 \%$ and $50 \%$ of deaths due to accidents happen in the first 5 and 30 minutes, respectively (Ministry of Health, Turkey 1992). Cardiovascular disease is the number one disease killer in Turkey. In addition, various other medical emergencies occur. In each of the above mentioned situations, it takes time for emergency professionals to arrive at the site of a medical emergency. This time gap requires the involvement of bystanders; if these people are trained in FA-BLS techniques, then victims' outcomes may be better.

Training first year university students in FABLS may be an effective way to increase the number of first aiders in Turkey. After graduation, these students will go to various regions of the country and play key roles in different sectors. Besides serving as first aiders, they will increase awareness about the importance of FA-BLS training and play a crucial role in advocacy of this subject.

Another problem is the lack of FA trainers. A possible solution to this problem is to train medical students to be FA trainers (Nelson 1982; Mowbray et al. 1987; Perkins et al. 1999). Then, they may be employed to train their university peers. Of course, it is impossible to train all of the university students in FA-BLS due to constraints such as lack of manpower, time, money, etc. However, having $10-20 \%$ of the population trained in BLS is considered to be sufficient (Bossaert 1993). Based on this information, a project entitled "Training 10\% of the first year university students in FA-BLS" was planned and conducted at Hacettepe University (HU).

This project had two phases. In the first phase, medical student first aid trainers (MeSFAT) were trained by academic trainers and in the second phase, first year university students were trained by these peer trainers under academic trainers' supervision. The purpose of this study was to assess the participants' evaluation of the project and to propose a new program to increase the number of first aiders in the country.

\section{Materials and Methods}

Phase I

Training the MeSFATs. At the end of the academic year 2002-2003, third year medical students in the HU Faculty of Medicine (FM) were informed about the MeSFAT training program. This group was selected for three reasons. First, they completed a 24-hour FA-BLS course in the first year of their education at HUFM. That course had basic similarities with the MeSFAT training program. Secondly, they had already completed the second and third years of the six-year medical education course in which the theoretical subjects of basic, medical and surgical sciences are taught. Thirdly, there would have been at least 3 more years until their graduation, so that they could have served as MeSFATs for as long as possible. 102 volunteer medical students attended a meeting that was held on June 6, 2003, during which they were informed about the project. A FA book (Bilir et al. 1998), which was developed by the staff of the Department of Public Health (DPH), was given to each candidate MeSFAT on June 27, 2003. This book covered all aspects of FA-BLS and also presented standard checklists for FA-BLS maneuvers. One chapter of the book was devoted to adult learning and teaching principles. This chapter had standard checklists for FA-BLS skills presentation, demonstration and coaching methods. The medical students were given a self-learning period of three months and after this period, they took an examination, consisting of 40 multiple choice questions. Four wrong answers cancelled one true answer. The cut-off mark for passing in exam was determined to be 70.0 out of 100.0 points ( 30 net correct answers). Of the 102 students who received the FA book, $45(44.1 \%)$ took the examination, which was held on October 2, 2003 and lasted for 45 minutes.

Thirty-seven students $(82.2 \%)$ who were successful in the examination had the opportunity to participate in the 12-hour FA-BLS training program, held on November $15-16,2003$. This program utilised practicebased learning. The details of the program are presented in Fig. 1. There were three A groups and three B groups, each of which was composed of six students though one of the groups had seven students. Each group was trained by one academic trainer. Four of the academic trainers were from the DPH and two of them were from the Department of Medical Education and Informatics 


\begin{tabular}{|c|c|}
\hline \multicolumn{2}{|r|}{ Day One } \\
\hline \multirow[t]{2}{*}{$09.00-12.00$} & BLS $^{1}$ in adults (All A groups) \\
\hline & BLS in infants (All B groups) \\
\hline $12.00-13.00$ & Lunch break \\
\hline \multirow[t]{3}{*}{$13.00-16.00$} & BLS in adults (All B groups) \\
\hline & BLS in infants (All A groups) \\
\hline & Day Two \\
\hline \multirow[t]{2}{*}{$09.00-10.00$} & Heimlich maneuver in adults (All A groups) \\
\hline & Heimlich maneuver in infants (All B groups) \\
\hline \multirow{2}{*}{$10.00-11.00$} & Heimlich maneuver in adults (All B groups) \\
\hline & Heimlich maneuver in infants (All A groups) \\
\hline \multirow[t]{2}{*}{$11.00-12.00$} & Recovery (Coma) position (All A groups) \\
\hline & Shock position and control of bleeding (All B groups) \\
\hline $12.00-13.00$ & Lunch break \\
\hline \multirow{2}{*}{$13.00-14.00$} & Recovery (Coma) position (All B groups) \\
\hline & Shock position and control of bleeding (All A groups) \\
\hline \multirow[t]{2}{*}{$14.00-15.00$} & Carrying a victim (All A groups) \\
\hline & $\begin{array}{l}\text { Application of fixation bandage, triangular bandage, slings, splints } \\
\text { (All B groups) }\end{array}$ \\
\hline \multirow[t]{2}{*}{$15.00-16.00$} & Carrying a victim (All B groups) \\
\hline & $\begin{array}{l}\text { Application of fixation bandage, triangular bandage, slings, splints } \\
\text { (All A groups) }\end{array}$ \\
\hline
\end{tabular}

Fig. 1. The 12-hour first aid and basic life support training program.

${ }^{1}$ Basic life support.

(DMEI). They were medical doctors. The academic trainers were experienced in this training and were also among the trainers of the 24-hour FA-BLS course, which was held in the first year of HUFM. The academic trainers emphasized demonstration, coaching techniques and communication skills during the training activities. They evaluated the participants' success using the standard check lists of FA-BLS maneuvers, which were presented to the medical students in the FA book. Another goal of the program was to ensure the participants' competency in each application, i.e., every single candidate MeSFAT should have mastered each of the maneuvers in the right order. The medical students' continuation in the program was required. The manikins and materials used in the training are presented in Fig. 2. The manikins were all products of the Laerdal Company (Laerdal Medical AS, Stavanger, Norway) and were made available on October 7, 2003. The training activities took place at HUFM's skills laboratory. Of the 37 candidate MeSFATs, 32 $(86.5 \%)$ achieved competency in the FA-BLS maneuvers. Five of the students were eliminated at this stage because they did not participate fully or attend the 12-hour FA-BLS training program.

The remaining 32 medical students studied a booklet, prepared by the DPH staff, on the basics of adult teaching skills for a few days. Then, the medical students were trained in teaching skills on December 6, 2003. In this step of the training, candidate MeSFATs were given a brief lecture about the principles of adult teaching methodology and the various techniques which are used, such as demonstration, coaching and communication skills. After this lecture, 5 groups were established. There were 6 medical students and one academic trainer in each group. One of the groups was composed of 7 students. One student did not attend the activities on this day, so he was asked to withdraw from the program. This time, 3 of the academic trainers were from the DPH and 2 of the academic trainers were from the DMEI. They evaluated the medical students using standard check lists for demonstration, coaching and communication skills. The desired competency level was targeted and achieved for each individual medical student. The 


\begin{tabular}{ll}
\hline Quantity $^{1}$ & \\
$3 / 4$ & Resusci Anne Full Body Skillguide w/Hard Case, Catalogue ${ }^{2}$ number: 310045, page 10 \\
$3 / 4$ & Resusci Baby w/Skillguide, Catalogue number: 140011, page 13 \\
$3 / 4$ & Choking Charlie, Catalogue number: PS-1800, page 25 \\
$3 / 4$ & Baby Anne Manikin, Catalogue page 14 \\
3 / 4 & Extri Kelly, Catalogue number: CK-1000, page 23 \\
$6 / 8$ & Elastic bandages \\
$6 / 8$ & Triangular bandages \\
$12 / 16$ & Rolling bandages \\
$24 / 32$ & Gause \\
$12 / 16$ & Wooden splints \\
$12 / 16$ & Lock pins \\
$60 / 80$ & Pins \\
$6 / 8$ & Selotapes \\
$6 / 8$ & Board markers \\
$6 / 8$ & Blunt tipped scissors \\
\hline
\end{tabular}

Fig. 2. The manikins and materials used in the first aid and basic life support training.

${ }^{1}$ MeSFAT / USFAD training programs.

${ }^{2}$ Laerdal Lifesaving Products Catalogue 2002.

medical students used role playing techniques, manikins, and other learning materials throughout the process. The duration of this step was 6 hours. In the end, 31 medical students $(96.9 \%)$ were certified as MeSFATs. This certification was valid only in HU and would last with the graduation from the University. In Turkey, The Ministry of Health has the right to authorize such training programs. However, as it is an experimental training program and the universities are allowed to conduct them, there is no such authorization for this course. In Fig. 3 the flow chart of the MeSFAT training program is presented.

An 11-item questionnaire to ascertain the medical students' sociodemographic characteristics, a 17-item evaluation questionnaire about the 12-hour FA-BLS training program, and a 13-item general evaluation questionnaire about the MeSFAT training program were applied to the medical students $(45,37,31$ participants, respectively).

\section{Phase II}

Training the University Student First Aiders (USFADs). All of the faculties and schools of the university were informed about the "USFAD training program" on September 29, 2003. On October 23, 2003, 129 first year university students attended an informational meet- ing about the program. This number comprised far below $10 \%$ of first year university students. The same FA books (Bilir et al. 1998) were distributed to them for the self-learning process. On November 5, 2003, a booklet on the structure and functions of the human body were distributed to this group. Only 64 students participated in the theoretical examination which was held on December 6, 2003. The cut-off point for a passing mark was 50 points and four of the questions on the test differed from those on the theoretical examination taken by the MeSFATs. The 4 questions related to teaching skills (for MeSFATs) were replaced by FA-related questions. Fifty-three $(82.8 \%)$ students passed the examination. Eleven students did not participate and 2 did not complete the practical training held in the skills laboratories. There were $4 \mathrm{~A}$ and $4 \mathrm{~B}$ groups during the practical training (Fig. 1). Five of the groups were composed of 5 students. The other three groups had 4, 6 and 7 students. Each of the groups were trained by one MeSFAT. In half of the groups 4 MeSFATs worked for two days. In the other half of the groups, 8 MeSFATs worked for one day. The same training materials, though in different quantities, were used (Fig. 2). Four academic trainers supervised the training program. On each training day, two academic trainers were on duty. Forty students successfully completed the practicals and were trained and eval- 
Third year medical students were invited for the project meeting

(at the end of academic year 2002-2003)

\begin{tabular}{|c|c|}
\hline$\downarrow$ & $\downarrow$ \\
\hline \multicolumn{2}{|c|}{$\begin{array}{l}102 \text { third year medical students attended the meeting } \\
\text { to be informed about the project (June } 6,2003 \text { ) }\end{array}$} \\
\hline$\downarrow$ & $\downarrow$ \\
\hline \multicolumn{2}{|c|}{$\begin{array}{l}\text { The first aid books were distributed } \\
\text { (June } 27,2003 \text { ) }\end{array}$} \\
\hline$\downarrow$ & $\downarrow$ \\
\hline \multicolumn{2}{|c|}{ Self-learning period (3 months) } \\
\hline$\downarrow$ & $\downarrow$ \\
\hline
\end{tabular}

45 third year medical students $(44.1 \%)$ took the theoretical examination (October 2, 2003)

$\downarrow \quad \downarrow$

37 third year medical students $(82.2 \%)$ who passed the theoretical examination, participated in the 12-hour FA-BLS ${ }^{1}$ training program (November 15-16, 2003)

$\downarrow \quad \downarrow$

32 third year medical students $(86.5 \%)$ who passed the practical evaluations received the booklets on adult teaching skills

$\downarrow \quad \downarrow$

32 third year medical students participated in 6-hour course on adult teaching skills (December 6, 2003)

$\downarrow \quad \downarrow$

31 third year medical students (96.9\%) passed the practical evaluations and certified as MeSFATs ${ }^{2}$ *11-item questionnaire for sociodemographic properties of the medical students

(45 third year medical students participated)

*6 academic trainers were in charge of the training and made the practical evaluations.

*17-item evaluation questionnaire for the 12 -hour

FA-BLS training program

(37 third year medical students participated)
*5 academic trainers were in charge of the training and made the practical evaluations.

Fig. 3. The flow chart of the medical student first aid trainer (MeSFAT) training program.

${ }^{1}$ First aid and basic life support.

${ }^{2}$ Medical student first aid trainer.

uated by 12 MeSFATs (December 20-21, 2003). The targeted competency level was achieved for each individual student. These students were certified as USFADs. The certification was valid only in the HU and will terminate upon graduation. In Fig. 4, the flow chart of the USFAD training program is given.

A 10-item questionnaire to ascertain the students' sociodemographic characteristics, a 16-item evaluation *13-item general evaluation questionnaire about the MeSFAT training program

(31 third year medical students participated) 
First year university students were invited for the project meeting (September 29, 2003)

$\downarrow \quad \downarrow$

129 first year university students attended the meeting to be informed about the project (October 22, 2003)

\begin{tabular}{|c|c|}
\hline$\downarrow$ & $\downarrow$ \\
\hline \multicolumn{2}{|c|}{ Self-learning period (1 month) } \\
\hline$\downarrow$ & $\downarrow$ \\
\hline \multicolumn{2}{|c|}{$\begin{array}{l}64 \text { first year university students }(49.6 \%) \text { took the } \\
\text { theoretical examination } \\
\text { (December } 6,2003 \text { ) }\end{array}$} \\
\hline$\downarrow$ & $\downarrow$ \\
\hline \multicolumn{2}{|c|}{$\begin{array}{l}\text { Of } 53 \text { first year university students }(82.8 \%) \text { who } \\
\text { passed the theoretical examination, } 42 \text { participated } \\
\text { in the } 12 \text {-hour FA-BLS }{ }^{1} \text { training program (December } \\
20-21,2003 \text { ) }\end{array}$} \\
\hline$\downarrow$ & $\downarrow$ \\
\hline
\end{tabular}

*First aid books were distributed.

*Booklets on the structure and function of the human body were distributed

(November 5, 2003) *10-item questionnaire for sociodemographic properties of the university students (64 first year university students participated)

Fig. 4. The flow chart of the university student first aider (USFAD) training program.

${ }^{1}$ First aid and basic life support.

${ }^{2}$ Medical student first aid trainer.

${ }^{3}$ University student first aider.

* 12 MeSFATs $^{2}$ were in charge of the training and made the practical evaluations.

$* 4$ academic trainers supervised the process.

*16-item evaluation questionnaire for the 12-hour

FA-BLS training program

*12-item general evaluation questionnaire for the USFAD $^{3}$ training program (40 first year university students participated)

\section{Results}

\section{Phase I}

Training the MeSFATs. The mean age of the 45 participants was 21.2 years (Standard deviation $=0.6$, min- $\max =20-23$, median $=21$ ). Of the 45 participants, $57.8 \%$ (26 students) were male and $42.2 \%$ (19 students) were female.

All of the medical students had previous FABLS training. They took a 24-hour FA-BLS course in the first year of their studies in the HUFM. The DPH was in charge of that course. The practice to theoretical ratio was $50 \%$ in that course. Twenty-four students had also taken FA-
BLS training during their driving license courses. When these students were questioned, it was found that the contents of the driving license FABLS course was mainly theoretical and shorter in duration. None of the students had trainer courses, previously.

At the beginning of the MeSFAT training program, $97.7 \%$ of the medical students (43 students) said that they thought they would be successful as FA trainers.

When they were asked how much time they thought they could spare as MeSFATs, $22.0 \%$ answered, (11 answers) "sufficient time that would not disturb their academic success". 
In the theory-based FA-BLS multiple choice examination, the mean numbers of correct, incorrect, and unfilled answers were 32.6 (Standard deviation $=2.8, \min -\max =26-37$, median $=33.0)$, 6.8 (Standard deviation $=2.5$, $\min -\max =2-12$, median $=6.0)$ and $1.7($ Standard deviation $=0.9$, min-max $=1-4$, median $=1.0$ ), respectively. The mean score of the theoretical examination was 77.1 (Standard deviation $=8.6$, min $-\max =$ 58.8-91.3, median = 78.1).

Tables 1 and 2 show the evaluation of the medical students about the 12-hour FA-BLS practical training program and the overall MeSFAT training program, respectively.

\section{Phase II}

Training the USFADs. The average age of the first year university students was 19.5 years (Standard deviation $=1.4$, min-max. $=18-26$, median $=19.0$ ). Of the first year university students, $50(78.1 \%)$ were female. $48(75.0 \%)$ of the first year university students had previously had FA training. These were mainly theory-based courses and of variable duration.

The average score on the theory-based FA examination was 64.0 (Standard deviation $=14.3$, min- $\max =21.9-87.5$, median $=68.8$ ). In the theory-based FA-BLS multiple choice examination, the mean numbers of correct, incorrect, and unfilled answers were 28.4 (Standard deviation $=4.7$, min-max $=15-36$, median $=30.0), 10.9($ Standard deviation $=4.6$, min- $\max =4-25$, median $=10.0$ ) and 2.1 (Standard deviation $=1.4, \min -\max =1-7$, median $=2.0$ ), respectively.

Tables 3 and 4 show the first year university students' evaluation of the 12-hour FA-BLS practical training program and overall USFAD training program, respectively.

At this phase of the project, the MeSFATs considered themselves to be successful in their trainer roles and they were very happy to be MeSFATs.

\section{Discussion}

\section{Phase I}

Training the MeSFATs. All of the medical students had previous FA-BLS training. They had the 24-hour FA-BLS course in the first year of HUFM. This may have positively influenced their performance in the MeSFAT training program. None of the students had previously taken FA trainer courses. So, perhaps this aspect of the MeSFAT training program presented the main challenge to medical students.

At the beginning of the program, the majority of the medical students $(97.7 \%)$ said that they thought they would be successful as FA trainers. Thus, even at the start, they displayed self-confidence, which is an important quality in a FA trainer.

Because the medical students were participating in the project as volunteers, naturally they only wanted to spare a limited amount of their free time for MeSFAT activities. This was an unforeseen issue. Before beginning the training, it would have been wise to establish rules concerning the level of time commitment the volunteers were expected to make.

In the theory-based FA-BLS multiple choice examination, the mean number of correct answers was 32.6 out of 40 questions. That fourth year medical students acheived such a low mean examination score may seem surprising but it must be kept in mind that four of the examination questions pertained to demonstration, coaching, and presentation skills, areas in which they had received no prior training. Nearly all of the medical students answered these four questions incorrectly. While the FA book presented to the students contained sufficient information on these topics, it is possible that the medical students neglected this section and instead focused on the medical aspects of FA-BLS.

The medical students' evaluation of the overall MeSFAT training program will be useful for improving the program in the future. When the "agree" and "definitely agree" categories were combined, the statements, "MeSFAT training program was successful as a whole" (100.0\%), "I am satisfied with the MeSFAT training program as a whole" (100.0\%) and "I will be successful as a MeSFAT" (96.8\%), had high support from the medical students. So, from their point of view, it can be concluded that the MeSFAT training pro- 


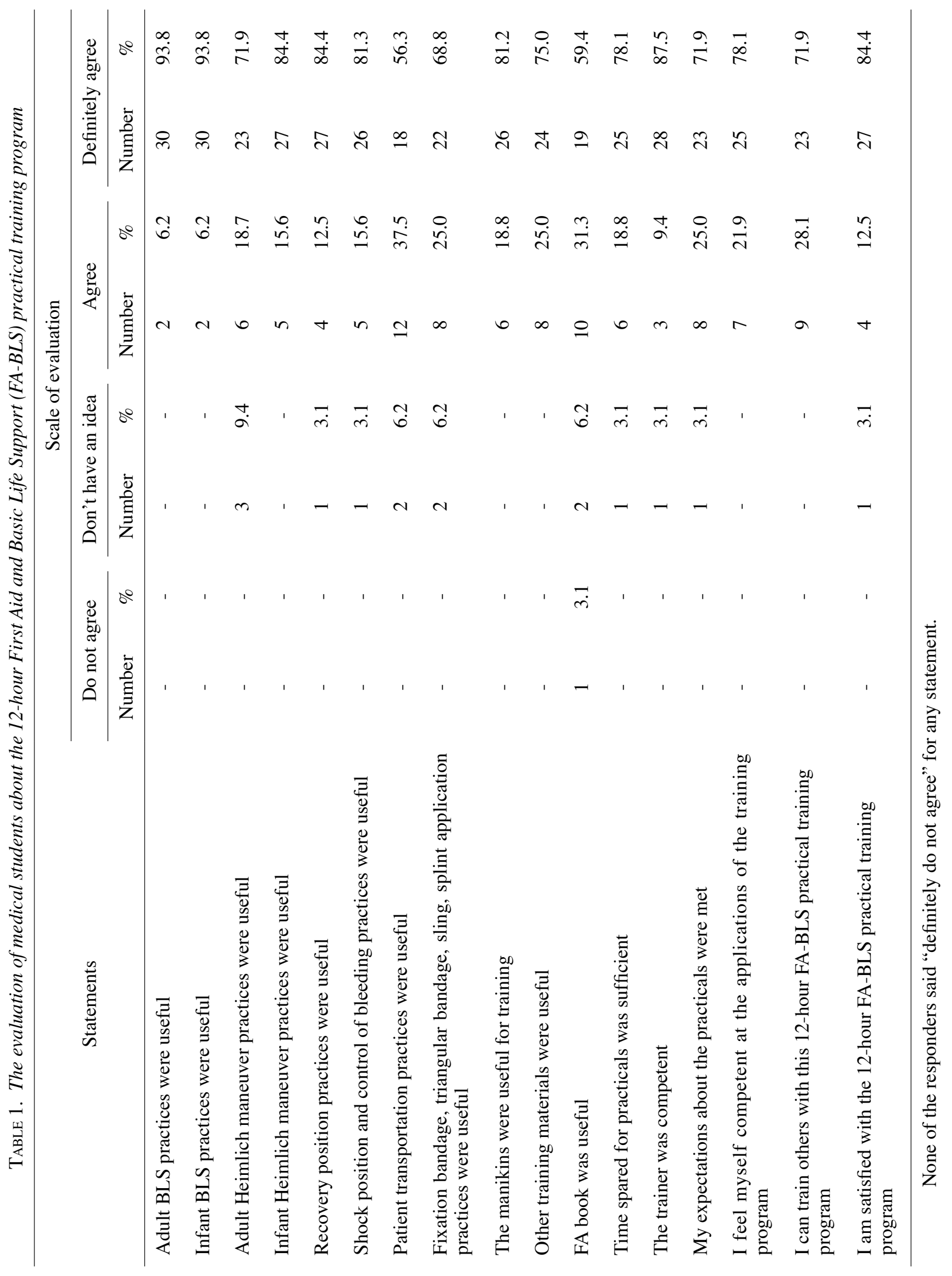


The Evaluation of First Aid and Basic Life Support Training

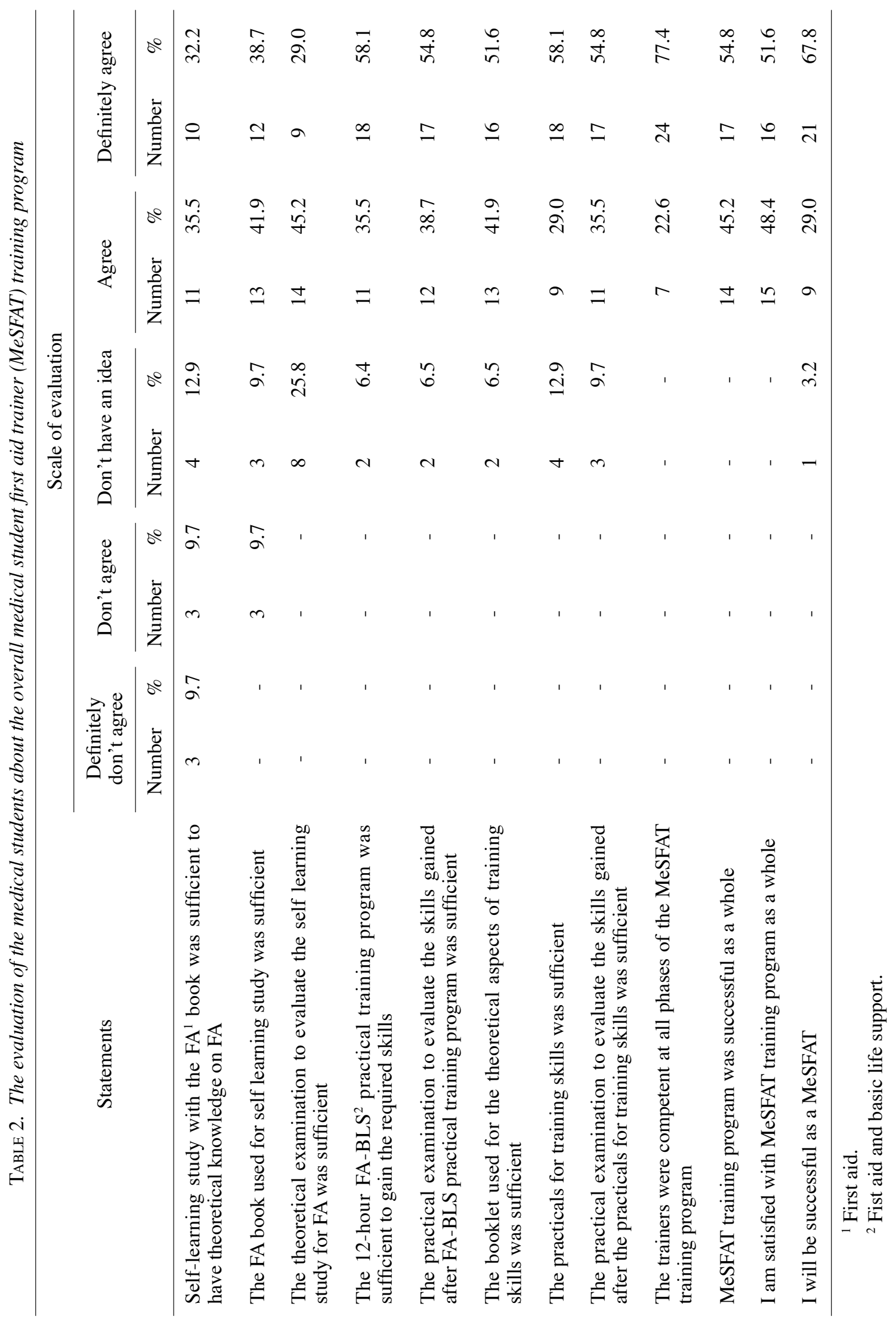


K.H. Altıntaş et al.

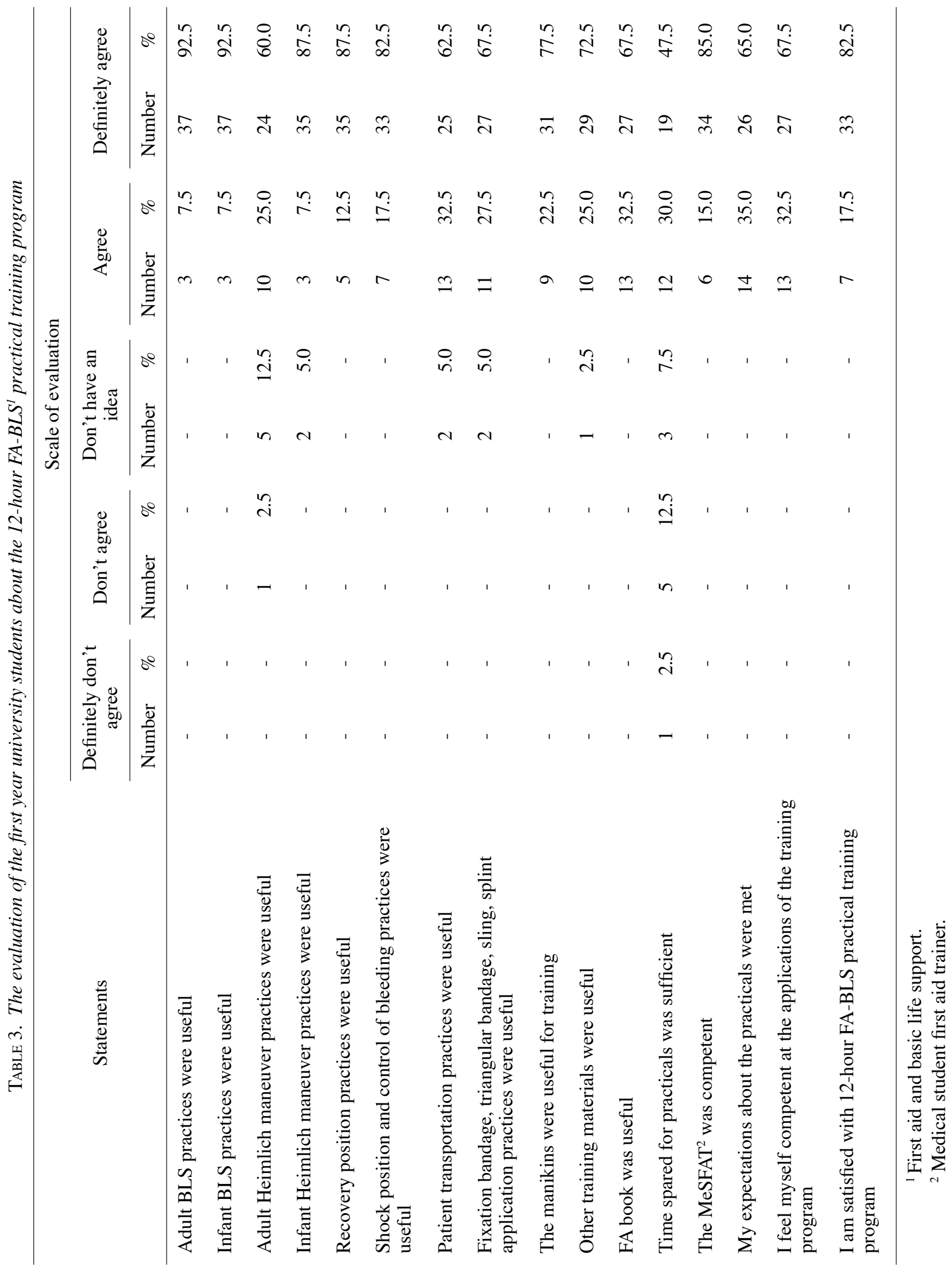


The Evaluation of First Aid and Basic Life Support Training

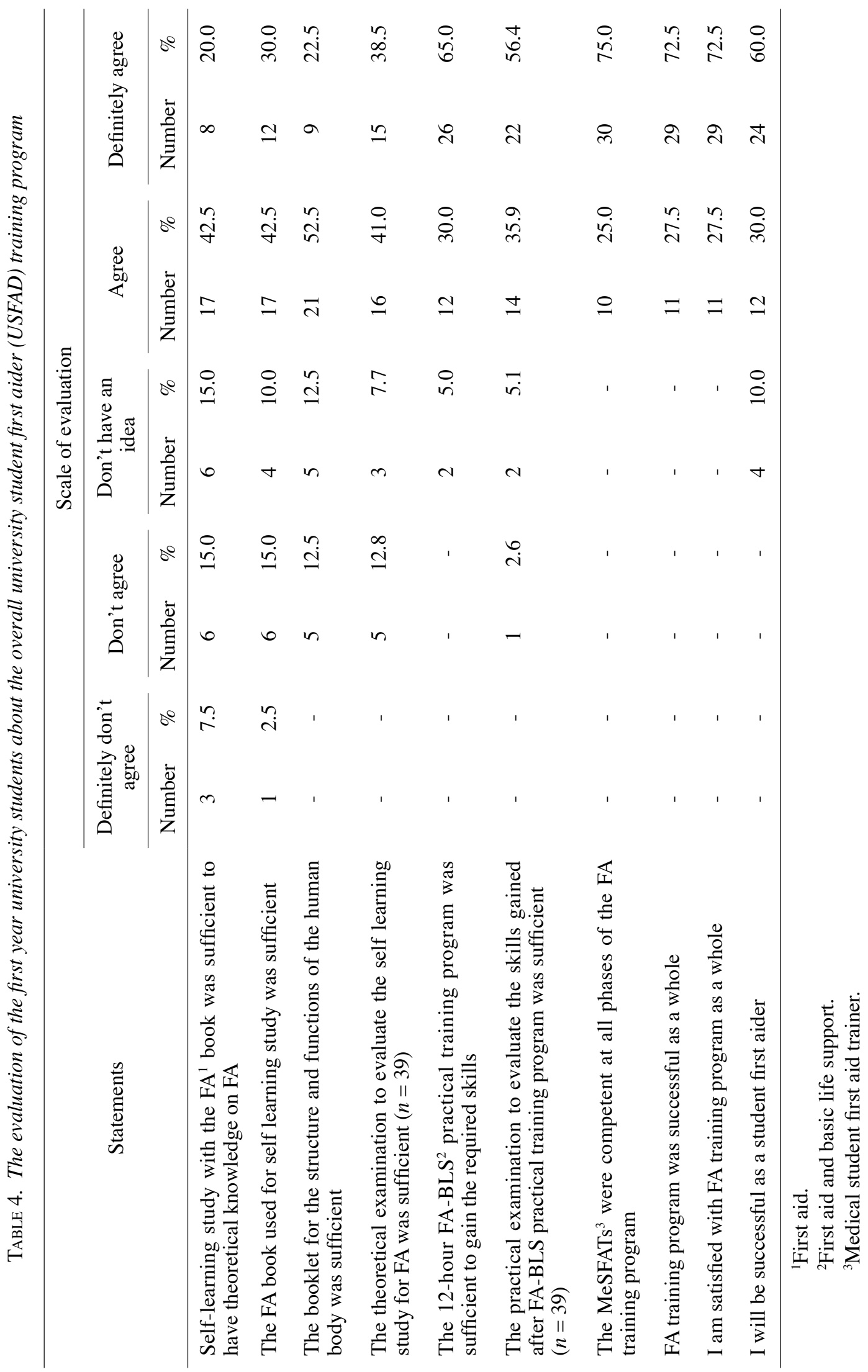


gram was successful.

After the MeSFATs were certified, the academic trainers realized that another step in the process, before certification, would improve the program. In the future, the MeSFATs should train their trainees under the supervision of the academic trainers at least once prior to certification. This would require that the candidate trainers participate in at least one training activity in which they will work as MeSFATs before officially completing the program.

\section{Phase II}

Training the USFADs. According to the first year university students, the MeSFATs were competent and the FA training program was successful. In addition, they were satisfied with the program overall. At this step, when also taking into account their own observations, the authors deemed the project a success. Twelve of the MeSFATs $(38.7 \%)$ were tested as trainers and showed that they were capable of providing effective FA training to other university students.

Based on their self-reported confidence after the FA-BLS training, it was found that 36 of the university students believed that they would be successful as USFADs. It would be beneficial to test USFADs in the field. However, it is difficult to observe them on duty in real settings because this would require the coincidental meeting of an emergency case, an academic trainer, and a USFAD simultaneously. Also, there is no surveillance system in place that tracks medical emergencies which happen at the HU. Thus, the survival statistics for emergency cases who received FA from a USFAD cannot be compared before and after the USFADs' training. Therefore, simple registry forms were given to USFADs to record the emergency cases they meet and to gather some descriptive data. After one year, these registry forms will be collected and that may give us a rough idea of the USFADs' effectiveness.

Another issue for both MeSFATs and USFADs is skill retention. The retention of skills decreases significantly shortly after training, sometimes to low levels, but still above pre-train- ing levels at 6-12 months (Eisenburger and Safar 1999). The investigators came to the conclusion that, after the students master the initial manikin practice, repeated practice with the manikins should be made available every 6-12 months (Eisenburger and Safar 1999). It may be a good approach to refresh the students' skills at regular intervals, perhaps once a year. Also, each training activity should be supervised by a sufficient number of academic trainers.

The concept of students teaching resuscitation is not new (Perkins et al. 1999). Medical students were found to be competent BLS instructors when teaching in a FA course (Mowbray et al. 1987). The Mount Sinai School of Medicine utilised second and third year students to deliver a FA-BLS course to its first year students (Nelson 1982). It is possible that students prefer to be taught by their peers, regardless of their peers' professional background (Nelson 1982). The students may perceive their peers to be delivering teaching at an appropriate level, in a non threatening manner, and having had the recent experience of being taught the material themselves (Perkins et al. 1999). The students might feel their trainers' credibility is increased by the fact of their coming from a healthcare background.

A new program for FA-BLS support training is described in this paper. This article points out the low number of first aiders in Turkey and the necessity of training Turkish people in various FA-BLS techniques, considering the contemporary situation in Turkey. Because some lifethreatening emergencies require high-level medical skills, this kind of FA-BLS training course should always be overseen by the appropriate medical and legal authorities.

In conclusion, according to both the participants and the authors, this program was successful and effective and may be used to increase the number of FA trainers and first aiders in the community. The outcome for Turkey may be particularly successful if other universities adopt this program and use it regularly.

\section{Acknowledgements}

We would like to thank Ms. Anna B. Flynn 
(Master of Health Science Candidate, Johns Hopkins Bloomberg School of Public Health) for her contributions in the editing of the paper in English.

\section{References}

Altıntaş, K.H. (1998) The Evaluation of Ambulance Services of Ankara Province Health Directorate Emergency Aid and Rescue Services (October 1995-September 1996). Thesis Study for Specialization in Public Health. T.C. Hacettepe University, Medical Faculty, Department of Public Health. Ankara, 1, 2, 49.

Bilir, N., Özvarış, S..B. \& Yıldız, A.N. (1998) Basic Knowledge in First Aid and Guide for First Aid Training Skills (For Trainers and Trainees). Hacettepe Public Health Foundation, Ankara.

Bossaert, L. (1993) The complexity of comparing different EMS systems-A survey of EMS systems in Europe. Ann. Emerg. Med., 22, 99-102.

Eisenburger, P. \& Safar, P. (1999) Life supporting first aid training of the public - review and recommendations. Resuscitation, 41, 3-18.

Liang, N., Shih, Y., Shih, F., Wu, H., Wang, H., Shi, S., Liu, M. \& Wang, B.B. (2001) Disaster
Epidemiology and Medical Response in the Chi-Chi Earthquake in Taiwan. Ann. Emerg. Med., 38, 549-555.

Ministry of Health, Turkey. (1992) The Reports of the First National Health Congress Study Groups. Ankara, 281-283.

Mowbray, A., McCullock, W.J.D., Conn, A.G. \& Spence, A.A. (1987) Teaching of cardiopulmonary resuscitation by medical students. Med. Educ., 21, 285-287.

Nelson, M. (1982) A first aid and CPR course for first year medical students. Med. Educ., 16, 7-11.

Perkins, G.D., Hulme, J., Shore, H.R. \& Bion, J.F. (1999) Basic life support training for health care students. Resuscitation, 41, 19-23.

Prime Ministry, Turkey. (2000) Press Release. (http: //www.Basbakanlik.gov.tr/Basbakanbasin/ Index.html).

Safar, P. (1986) Resuscitation potentials in mass disasters. Prehosp. Disaster Med., 2, 34-47.

Sarp, N. (1999) Disaster Management in Health Care. Deprem Araştırma Bülteni, 81, 55-100.

Waeckerle, J.F. (1991) Disaster planning and response. N. Engl. J. Med., 324, 815-821. 